\title{
Prevention of menstrual migraine with perimenstrual transdermal 17-beta-estradiol: a randomized, placebo-controlled, double-blind crossover
}

\author{
Anna Almen-Christensson, Mats Hammar, Lotta Lindh-Åstrand, \\ Jan Brynhildsen and Anne-Marie Landtblom
}

\section{Linköping University Post Print}

N.B.: When citing this work, cite the original article.

Original Publication:

Anna Almen-Christensson, Mats Hammar, Lotta Lindh-Åstrand, Jan Brynhildsen and AnneMarie Landtblom, Editorial Material: Prevention of menstrual migraine with perimenstrual transdermal 17-beta-estradiol: a randomized, placebo-controlled, double-blind crossover study, 2011, Fertility and Sterility, (96), 2, 498-500.

http://dx.doi.org/10.1016/j.fertnstert.2011.05.089

Copyright: Elsevier Science B.V., Amsterdam. http://www.elsevier.com/

Postprint available at: Linköping University Electronic Press http://urn.kb.se/resolve?urn=urn:nbn:se:liu:diva-69979 
F \& S Almén-Cristensson et al revised

Running title: Prevention of menstrual migraine 


\section{Prevention of menstrual migraine with perimenstrual transdermal}

\section{7- $\beta$-estradiol -a randomized, placebo-controlled, double-blind}

\section{cross-over study}

*Almén-Christensson Anna, MD, *Hammar Mats, MD, PhD, *Lindh-Åstrand Lotta, RN, PhD, **Landtblom Anne-Marie, MD, PhD, *Brynhildsen Jan, MD, PhD

*Division of Obstetrics \& Gynecology, Department of Clinical and Experimental Medicine, Faculty of Health Sciences, Linköping University, Linköping, Sweden.

** Division of Neurology, Department of Neuroscience and Locomotion, Faculty of Health

Sciences, Linköping University, Linköping, Sweden

Corresponding author and request for reprints:

Jan Brynhildsen

Obstetrics \& Gynecology, Division of Women and Child Healh, Department of Clinical and Experimental Medicine

Faculty of Health Sciences

Linköping University

SE-58185, Linköping

Sweden

Tel: + 4613222000

Fax: +4613148156

e-mail: jan.brynhildsen@lio.se

\section{Source of support:}

Schering Nordiska AB, Stockholm, kindly supplied patches with estradiol or placebo

Clinical Trials.gov: Identification number NCT00204074 
F \& S Almén-Cristensson et al revised

\section{Capsule}

In a double-blind, placebo-controlled randomized cross-over trial estradiol treatment was not shown to be superior to placebo in the prevention of menstrual migraine attacks 


\begin{abstract}
The effect of treatment with percutaneous estradiol $(100 \mu \mathrm{g}$ estradiol/24h) during two weeks perimenstrually on the number and severity of menstrual migraine attacks was studied in 27 women in a randomized, placebo-controlled double blind cross over trial. We were not able to demonstrate any difference between estradiol supplementation and placebo on the number or severity of migraine attacks but both regimens showed significant effects compared to pretreatment.
\end{abstract}

This study was registered in Clinical Trials.gov: Identification number NCT00204074

Key words: menstrual migraine, estradiol, RCT 
After puberty migraine is approximately three times more common in women than in men and approximately $18 \%$ of all women of fertile ages suffer from migraine(1).The gender difference of migraine and the nature of menstrual migraine suggest a hormonal trigger. Pure menstrual migraine is defined by the International Headache Society (IHS) as migraine attacks that occur two days before to three days after the onset of bleeding and at no other times of the menstrual cycle. Attacks should be without aura and present in two out of three menstrual cycles (2). Sommerville concluded that the rapid decrease in serum concentrations of estradiol triggered migraine attacks in certain women. The estradiol drop also requires a preceding high serum concentration of more than a few days to be able to trigger a migraine attack, explaining why estradiol drops after ovulation seldomly are associated with migraine attacks (3, 4). In women with menstrual migraine the stability rather than the concentrations of estradiol might be crucial to avoid and prevent attacks. Treatment may cause stability at low estrogen concentrations either by use of GnRH analogues or danazole $(5,6)$ or at higher concentrations using combined oral contraceptives or estrogen supplementation perimenstrually $(7,8,9,10)$. There seems to be a dose-response pattern as better results have been reported with use of a higher estradiol dose witch also suggest a critical concentration (11).

The aim of this study was to test the hypothesis that a high dose estradiol administered perimenstrually would reduce the number, duration and severity of migraine attacks in women with pure menstrual migraine.

Pure menstrual migraine was defined according to IHS (2). There were two study centers (University Hospital, Linköping Sweden and the County Hospital, Jönköping, Sweden). The women had to be 18-45 years old, otherwise healthy and have regular menstrual cycles (26-30 
F \& S Almén-Cristensson et al revised

days). No hormonal contraception was allowed and adequate wash-out periods were demanded if the women had used contraceptive injectables, implants or intrauterine progestin

At the screening visit and end of trial, a thorough general medical examination and a gynecological examination including ultrasound was conducted. Each woman was informed in both writing and orally and thereafter she gave her written informed consent After screening, the woman filled in a diary prospectively in order to confirm regular menstrual periods and the diagnosis of pure menstrual migraine. An experienced neurologist (AML) confirmed the diagnosis.

The treatment was administered transdermally as two patches with $50 \mu \mathrm{g}$ estradiol/24h (Climara ${ }^{\circledR}$, Schering Nordiska AB, Stockholm) or placebo in seven-day patches. Seven days before the estimated onset of the menstrual bleeding the woman started treatment. Two new patches replaced these patches after seven days and were then followed by two weeks without treatment, i.e. two weeks of treatment each menstrual cycle.

This procedure was repeated three times (i.e. during three consecutive menstrual cycles). After one month of wash-out, women crossed-over to the treatment they had not received the first three consecutive cycles (Supplemental material - Flow chart).. The research nurse delivered the patches before the start of each treatment period.

The women recorded menstrual data, use of patches, the number of migraine attacks and severity of the attacks (mild-moderate-severe) (12). A severe attack was defined as an attack that prevented the patient from work or other scheduled activities.

Compliance to treatment was evaluated from unused patch count and the number of migraine attacks each cycle as well as the average number of attacks was calculated. 
Statistical evaluation was performed using Wilcoxon's signed-rank test. To be able to detect a difference between treatments of one attack each cycle or one step decrease in severity at a 5\% significance level, with a $90 \%$ power, 29 patients had to fulfill the treatment. Estimating a $20 \%$ dropout rate, 36 patients were planned to be included.

The Regional Ethical review Board in Linköping and the Swedish Medical Products Agency approved the study, which was conducted according to Good Clinical Practice.

A total of 83 patients were screened for inclusion and totally 38 patients were included. Eleven patients were excluded from the study. Three women didn't fulfill the criteria for inclusion and one woman used the patch incorrectly. Six women didn't complete the study because of adverse events (Supplemental material - Flow chart). The women were on average 39,6 years $(+/-4,3)$ Both estradiol and placebo treatment reduced the number of migraine attacks as compared to pre-treatment. There were, however, no significant differences between estradiol and placebo on the number of migraine attacks or the severity of migraine attacks (table 1). Neither were there any differences in the number of days of sick leave from work between the treatment period and the placebo period.

Patch count yielded a result slightly above $100 \%$ due to the fact that some patients used an extra patch because the originally placed patch was lost.

Six women discontinued due to adverse events. Two of these women reported increased headache, two women discontinued because of local skin reactions, one due to nausea and one because of increased blood pressure. One woman became pregnant and was therefore excluded. Two women reported minor disturbances of the menstrual cycle but both these women continued. No serious adverse events occurred. 
Table 1. Number of migraine attacks, severity of headache, intensity of attack and sick-leave. Values are presented as median and range. Wilcoxon signed-rank test. Intensity means the patients' subjective rating of the attack including not only headache but also related symptoms such as nausea, vomiting, etc.

\section{Pre-treatment $\quad$ Estradiol}

vs

VS

Pre-treatment Estradiol Placebo Estradiol

\section{Placebo Placebo}

Number of menstrual migraine

attacks/cycle

$1.5(1-3) \quad 1.0(0-2) \quad 1.0(0-2,5)$

$\mathrm{p}=0.0001 \quad \mathrm{p}=0.0004$

$\mathrm{p}=0.92$

Average severity of headache

in migraine attacks/cycle $1.75(1-3) \quad 1.67(0-3) \quad 1.67(0-2,5)$

$$
\mathrm{p}=0.96
$$

Average intensity of the migraine attacks/cycle

$$
\mathrm{p}=0.82
$$$$
1.5(1-2,5) \quad 1.5(0-3) \quad 1.6(0-2,5)
$$$$
\mathrm{p}=0.13
$$$$
\mathrm{p}=0.12
$$ 
In the present study we were not able to demonstrate any difference between treatment with $100 \mu \mathrm{g}$ transdermal $17 \beta$-estradiol or placebo on the number, duration or severity of menstrual migraine attacks.

Both treatments had significant effect on migraine attacks compared to pre-treatment.

The strict inclusion criteria made it difficult to recruit patients. Therefore, we decided to break the code and stop the study when only 27 patients had fulfilled the study. As a consequence, we did not reach the planned sample size and statistical power. However, when estimating two more patients with maximum effect of active treatment, the lack of difference between estradiol and placebo would have remained.

Previous placebo controlled studies have shown conflicting results. Studies of treatment with 25 to $50 \mu \mathrm{g}$ estradiol/24h have failed to demonstrate any effect compared to placebo $(9,10,11)$. whereas $100 \mu \mathrm{g}$ estradiol/24h have been reported to be effective (11). Also studies using $1,5 \mathrm{mg}$ estradiol transdermal gel have reported good effects $(7,8,13)$. The serum concentrations of estradiol in women using patches with $100 \mu \mathrm{g}$ estradiol may produce even higher serum concentrations of estradiol $(14,15,16)$ than $1,5 \mathrm{mg}$ estradiol gel and the lack of difference in results between estradiol and placebo could most probably not be explained by an insufficient dose of estradiol.

MacGregor et al (13) used a fertility monitor to establish the time of ovulation for timing of the treatment. Such a regimen is more reliable concerning the timing but is difficult to use in everyday life. We relied on the women's self reported menstrual data and the pre-treatment 
F \& S Almén-Cristensson et al revised

diaries confirmed regular cycles.

The women in our study were treated during a prolonged time (14 days, starting seven days before estimated start of the menstrual bleeding) in order to maintain a higher serum concentration of estradiol and to avoid influence of a variation in cycle length, whereas other studies generally treated women for seven days totally $(7,8,13)$. The aim of this regimen was to make sure that serum concentrations of estradiol would be stable at the time of the anticipated start of the bleeding and migraine attacks. This regimen minimizes the risk of insufficient timing of the treatment due to variable menstrual cycle length.

According to IHS-guidelines for controlled clinical trials of drugs in migraine (17) at least 48 hours of freedom from symptoms should have occurred if the headache should be identified as a new migraine attack. Otherwise it should be considered as relapse. In the present study, the exact hour of the onset of the attack was not recorded, only the day and the duration of the attack. Therefore we have included both new attacks and attacks that maybe could be classified as a relapse. We consider it unlikely that this slight modification should have had any impact on the interpretation of the results as we used the same classification during all cycles and consequently the same method was used for both active and placebo treatment.

In conclusion we found no benefit in treating women with menstrual migraine with transdermal estradiol $100 \mu \mathrm{g} / 24 \mathrm{~h}$ versus placebo, however, both treatments improved migraine headache in the group of women studied. The results are in contrast to previous studies. 
F \& S Almén-Cristensson et al revised

Acknowledgements: The authors would like to thank Dr Birgitta Gustafsson-Borg and Dr JanÅke Åkesson for recruiting patients and nurses/midwives Gunn Johansson, Christina Ramsö and Lena Skaring-Thorssén for help with handling the patients. 


\section{References}

1) Lipton RB, Stewart WF, Diamond S, Diamond ML, Reed M. Prevalence and burden of migraine in the United States: data from the American Migraine Study II.

Headache. 2001;41(7):646-57.

2) Headache Classification Committee of the International Headache Society. The International Classification of Headache Disorders: $2^{\text {nd }}$ edition. Cephalalgia 2004;24 (Suppl. 1):9-160

3) Somerville BW. The role of estradiol withdrawal in the etiology of menstrual migraine. Neurology 22:355-365, 1972

4) Somerville BW. Estrogen-withdrawal migraine. I. Duration of exposure required and attempted prophylaxis by premenstrual estrogen administration. Neurology 25:239-244, 1975

5) Lichten EM, Bennett RS, Whitty AJ, Daoud Y. Efficacy of danazol in the control of hormonal migraine. J Reprod Med. 1991;36(6):419-24.

6) Murray SC, Muse KN. Effective treatment of severe menstrual migraine headaches with gonadotropin-releasing hormone agonist and "add-back" therapy. Fertil Steril. 1997;67(2):390-3. 
7) DeLignières B, Vincens M, Mauvais-jarvis P, Mas JL, Touboul PJ, Bousser MG. Prevention of menstrual migraine by percutaneous estradiol. Br Med J 1986;293:1540.

8) Dennerstein L, Morse C, Burrows G, Oats J, Brown J, Smith M. Menstrual migraine: a doubleblind trial of percutaneous estradiol. Gynecol Endocrinol 1988;2:113-20.

9) Smits VG, van der Meer YG, Pfeil JPJM, Rijnierse JJMM, Vos AJM. Perimenstrual migraine: effect of Estraderm TTS and the value of contingent negative variation and exteroceptive temporalis muscle suppression test. Headache 1993;34:103-6.

10) Pfaffenrath V: Efficacy and safety of percutaneous estradiol vs placebo in menstrual migraine. Cephalalgia 1993; 13:Suppl 13:244.

11) Pradalier A, Vincent D, Beaulieu P, Baudersson G, Launey J-M. Correlation between estradiol plasma level and therapeutic effect on menstrual migraine. In: Rose F, ed. New advances in headache research. London: Smith-Gordon, 1994: 129-132.

12) MacGregor EA, Hackshaw A; Prevalence of migraine on each day of the natural menstrual cycle. Neurology 2004:63:351-53

13) MacGregor EA, Frith A, Ellis J, Aspinall L., Hackshaw A Prevention of menstrual attacks of migraine. A double-blind placebo-controlled crossover study. Neurology 2006;67:2159-2163 
14) Pharmaceutical Agents in Sweden (FASS), pp 493, 613, Elanders, Kungsbacka, Sweden, 2005.

15) Taggart W, Dandekar K, Ellman H, Notelowitz M. The effect of site application on the trancutaneous absorption of 17- $\beta$ estradiol from a transdermal delivery system (Climara). The journal of The North American Menopaus Society. 2000:7: 364-369

16) Piippo S, Lenko H, Kainulainen P, Sipilä I. Use of percutaneous estrogen gel for induction of puberty in girls with Turner syndrome. Endocrinol Metabol 2004: 89: 3241-3247

17) International Headache Society Clinical Trials Subcommittee. Guidelines for controlled trials of drugs in migraine: second edition. Cephalalgia, 2000, 20, 765 \pm 786 
F \& S Almén-Cristensson et al revised

Supplemental material. Participant flow-chart.

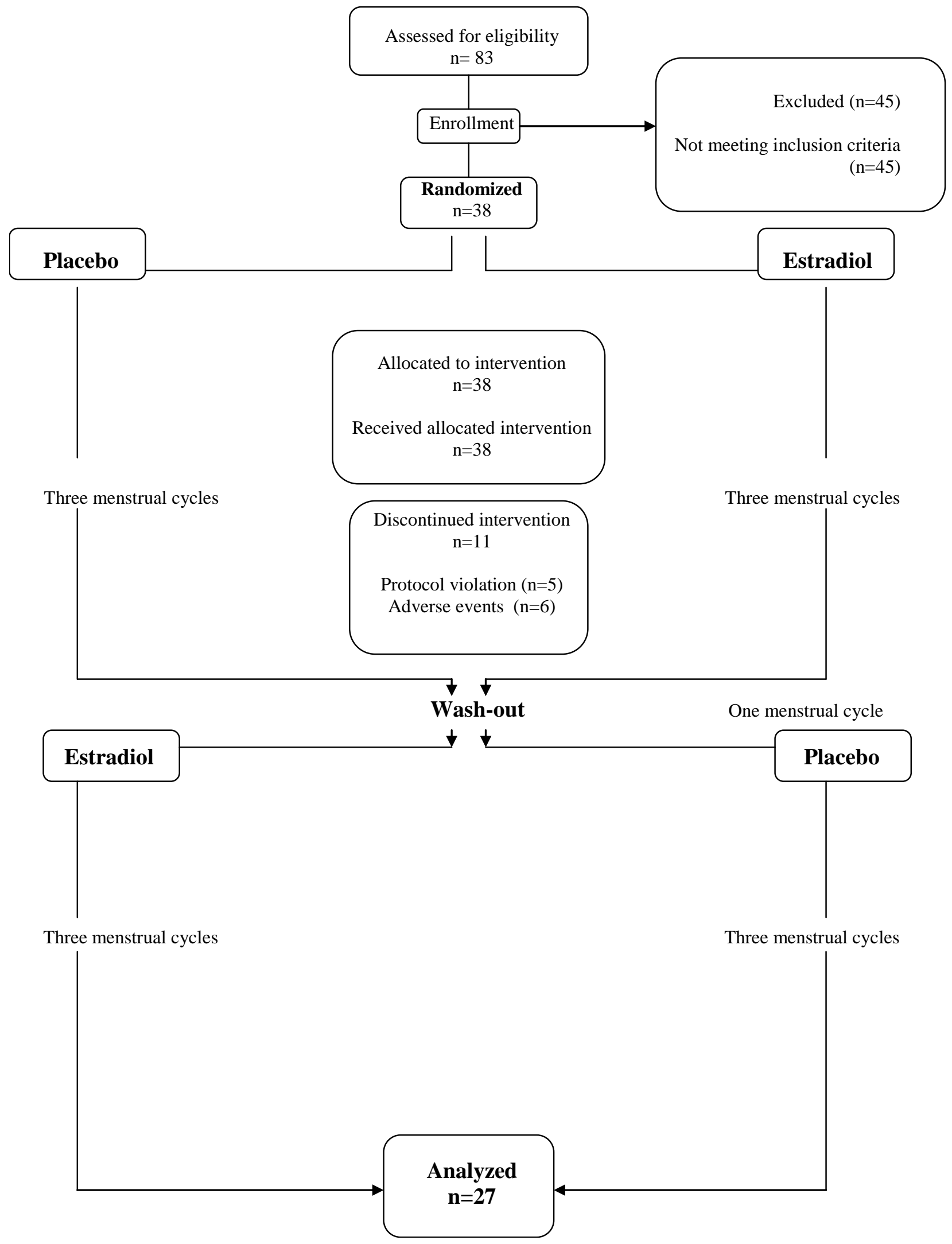

